Does a Mandatory

Telemedicine Call Prior

to Visiting a Physician

Reduce Costs or Simply

Attract Good Risks?

Chantal Grandchamp and

Lucien Gardiol 



\section{Does a Mandatory}

Telemedicine Call Prior

to Visiting a Physician

Reduce Costs or Simply

Attract Good Risks?

Chantal Grandchamp ${ }^{1}$ and Lucien Gardiol ${ }^{2}$

${ }^{1}$ Institute of Health Economics and Management(IEMS), University of Lausanne.Corresponding author:

chantal.grandchamp@unil.ch

2 Institute of Health Economics and Management(IEMS), University of Lausanne.

This text is not to be cited without the permission of the authors.

Working Paper $n^{\circ}$ ๑8-01

March 2008

Institute of Health Economics and Management (IEMS)

UNIL Dorigny

Extranef

1015 Lausanne

Switzerland

Phone +41 (0)21 6923320

Fax +41(0)21 6923655

www.hec.unil.ch/iems 


\title{
DOES A MANDATORY TELEMEDICINE CALL PRIOR TO VISITING A PHYSICIAN REDUCE COSTS OR SIMPLY ATTRACT GOOD RISKS?
}

\author{
Chantal Grandchamp* $\quad$ Lucien Gardiol ${ }^{\dagger}$
}

\begin{abstract}
This paper aims to estimate empirically the efficiency of a Swiss telemedicine service introduced in 2003. We used claims' data gathered by a major Swiss health insurer, over a period of six years and involving 160000 insured adults.

In Switzerland, health insurance is mandatory, but everyone has the option of choosing between a managed care plan and a fee-for-service plan. The present paper focuses on a conventional fee-for-service plan including a mandatory access to a telemedicine service; the insured are obliged to phone this medical call centre prior to visiting a physician. This type of plan generates much lower average health expenditures than a conventional insurance plan. Reasons for this may include selection, incentive effects or simply efficiency.

In our sample, about $90 \%$ of the difference in health expenditure can be explained by selection and incentive effects. The remaining $10 \%$ of savings due to the efficiency of the telemedicine service amount to about SFr 150 per year per insured, of which approx. $60 \%$ is saved by the insurer and $40 \%$ by the insured. While the plan is cost-effective, the big winners are the insured who not only save monetary and nonmonetary costs, but also benefit from reduced premiums.
\end{abstract}

KEYWORDS: health, insurance, selection, efficiency, telemedicine

*IEMS (Institute for health economics and management), University of Lausanne, Extranef, 1015 Lausanne-Dorigny, Switzerland. Corresponding author: chantal.grandchamp@unil.ch, phone: 00412169236 58, fax: 0041216923365.

${ }^{\dagger}$ IEMS, University of Lausanne.

${ }^{0}$ Financial support from Medgate SA is gratefully acknowledged.

${ }^{0}$ We thank Hanspeter Bickel from KPT Insurance for the data and for informational support. We are also grateful to Andy Fischer, Lorenz Fitzi, Samantha Foulger, Peter Fuchs, Pierre-Yves Geoffard, Alberto Holly, Thomas Lufkin, Jan von Overbeck and Timo Rimner for remarks and comments. Any remaining errors are our own. 


\section{Introduction}

In 2003 a Swiss health insurer (KPT) launched a new plan whereby the insured, in exchange for a premium rebate, would be obliged to seek advice from a telemedicine service prior to consulting a physician. This plan is known as the "Integriertes Stufenmodell (WIN) LK1", hereafter the "Winwin"plan. The raw data show that the health expenditure of enrolees to this new plan is half that of those who remained with their original plan. To what extent then are these spending differences due to the efficiency of the Winwin plan?

To answer this question, three methods could be used. The first concerns checking all bills and phone calls with the aim of inferring what would have occurred if the insured had not phoned the telemedicine service. Obviously this is almost impossible to apply ex-post. To the question "Would you have gone to the physician if telemedicine was not available?", any answer given by enrolees will almost certainly be influenced by the fact that they know whether the visit to the physician was helpful or not. This analysis has to rely on a powerful model capable of predicting how each enrolee will react. Regrettably, such an approach is far beyond the scope of the present research.

The second method involves running a new RAND experiment and randomly selecting specific enrolee samples. This is far beyond the budget of the present research.

The third method, which we use here, takes relatively aggregate data and constructs a robust model that can distinguish to what extent the differences in spending are due to selection and to incentives; any remaining differences not explained by these two nuisance factors are attributed to the efficiency effect.

The literature on telemedicine deals mainly with new technology, medicine and economic evaluation. The economic literature on health insurance efficiency focuses mainly on the efficiency of managed care plans, such as HMOs. But the problem and therefore the methodology are exactly the same than in our own research. Below is a brief summary of the main findings from existing research.

The RAND Experiment included a section which dealt with HMOs and may be considered as a reference. Newhouse et al. (1996) analysed and compared health expenditure in an HMO plan and in a fee-for-service plan. The spending differences between the two plans is attributed to varying hospitalisation rates; the HMO plan spent more on preventive visits, but decreased the hospitalisation rate by about $40 \%$. Newhouse et al. attribute 
this to differences in patient treatment. However, no difference was found in outpatient expenditures. Buchanan et al. (1996) also adopted the second method and used experimental data to estimate cost reductions in the US Medicaid system by comparing a staff HMO to a fee-for-service plan. The savings were linked to the probability of using care; once health expenditures were positive, the amount of services received was the same.

Other studies (including ours) used the third method to estimate efficiency. For example, Shin and Moon (2007) used the Medical Expenditure Panel Survey to estimate the cost containment performance of HMO plans. They found little evidence of selection in favour of the HMO plan and no evidence of significant cost-savings, even after they controlled for potential selection bias. Lehmann and Zweifel (2005) used panel data from a Swiss insurer to estimate the efficiency of an HMO plan. They found that the plan lowered average health expenditure by about $62 \%$ compared to the conventional fee-for-service plan. They also concluded that the efficiency gain accounted for two-thirds of this cost decrease, and selection for a mere one third. Finally, Deb et al. (2006) used simultaneous equations applying econometric simulation techniques to estimate the treatment effects of managed care plans on the utilization of health care services, while controlling for the endogeneity of the insurance plan. They found evidence of self-selection in a managed care plan and estimated that the number of visits to a physician or an emergency room were significantly higher when an individual was enrolled in an HMO plan.

In the Winwin plan, the insured must first contact a medical call centre before visiting a physician. Physicians working at the call centre advise on the timing and the type of medical care needed. They provide callers with a given timeframe during which the patient can visit a physician. However, should this period elapse and the patient still requires a further consultation with a physician, he/she is obliged to contact the telemedicine centre again. In selected cases, the physician can prescribe drugs and/or propose selftreatment.

This procedure is expected to yield two main benefits: preventing futile physician visits and offering better guidance and timing in relation to health care use. The main consequences are the delivery of fewer primary health care consultations, and a reduction in the attendant investigation and treatment costs. Given that these visits are usually inexpensive but frequent, the amount of efficiency gain is presumed to be limited. Individual histories may well include persons, who visit a doctor after the advice and are saved by a costly treatment, but would have died overnight if they did not. This is certainly a social gain, but this is a cost in monetary terms. This research 
covers only monetary costs and therefore foresees some benefits of the plan.

The insured generally regard this mandatory call as a burden, or as a loss in freedom. The health insurer therefore offers premium rebates to anyone joining the plan. For individuals in good health who do not intend to consult a physician in the coming year, this reduced premium is considered as a free gift. In contrast, patients with a diagnosed chronic disease are aware that they will need health care anyway, so a mandatory prior phone call simply constitutes a burden. This raises the suspicion that people who opt for the Winwin plan are on average in better health than those who do not.

The structure of our paper is as follows: We present briefly the general context in which the plan was launched (2), the data set (3), the method (4), the results (5) and as a conclusion discuss the impact of our findings for the Swiss health insurance sector today (6).

\section{Health insurance and telemedicine in Switzer- land}

Since 1996, the Federal Law on Health Insurance (LAMal) has made health insurance compulsory for all individuals who are resident in Switzerland. They can choose between several health insurers, each of which is legally obliged to offer a broad basic package of health care services, procedures and treatments. These cover sickness, accidents and maternity health care. Accident coverage is mandatory but since most employees are already covered through their employers, they are free to omit it from their health insurance package.

Premiums vary across insurance funds, but flat rates apply to a given plan and to a given deductible. In particular, no discrimination based upon age, gender or health status is allowed. A risk-adjustment scheme between insurance funds reduces the incentives to select risks. However, the present risk-adjustment Swiss formula is based exclusively on age, gender and region. Moreover, premium reductions for a higher deductible are limited by law in order to curb risk selection. Finally, the state subsidises health insurance premiums of those in the low-income bracket, implementing a form of redistribution between income levels.

Private not-for-profit insurance firms offer a variety of contracts including the conventional fee-for-service plan as well as a range of managed care plans. Though the conventional fee-for-service insurance plan is still the most common ( $90 \%$ of the population in 2005), the popularity of the managed care plan has grown over time. 
There are two types of managed care plan: the first involves a reduced choice of physicians (HMOs and gatekeeper plans), while the second places no restrictions on the choice of physician but makes a phone call to a telemedicine service mandatory prior to any medical visit (except emergency and preventive care). Managed care plans and their premiums must be approved by the state health regulator.

In addition, all insurance contracts include a mandatory deductible of SFr $300^{1}$ on yearly expenditures for adults, a co-payment rate of $10 \%$ once the deductible level has been reached and a cap on yearly payments equal to SFr 700 for adults and SFr 350 for children in addition to the deductible. Furthermore, different deductible levels, set by law, can be offered by insurance companies in return for a reduced premium, but the minimum deductible of SFr 300 always remains for adults. Currently, optional deductibles are equal to SFr 500, 1 000, 1500,2000 or 2500 for adults and SFr 100, 200, 300, 400, 500 or 600 for children. Note that maternity is still treated as a sickness in Switzerland, yet no co-payment or deductible is applied to standard maternity expenditures.

We compare two different insurance plans: a conventional fee-for-service insurance plan and a "light" version of the managed care plan, which obliges the insured to contact a telemedicine service prior to any medical visit. The health care services and treatments covered, the deductible proposed and the co-payment scheme are the same for both plans. The only differences between the two are the mandatory use of the telemedicine service and the reduced premium rates for the managed care plan ${ }^{2}$. Therefore, if the sampled insured in each plan were comparable, we could directly estimate the efficiency effect of the use of a telemedicine service as the difference in mean expenditures.

\section{Description of the data set}

We use administrative data from KPT, one of the largest health insurers in Switzerland, which proposes both the regular fee-for-service plan and the plan featuring a telemedicine service. KPT has offered its "Winwin plan" since 2003. In 2001 and 2002, individuals could choose between the general insurance plan (OKP plan) and another managed care plan (GP -

\footnotetext{
${ }^{1} 1$ Swiss franc equals approximately 0.61 Euros or $\$ 0.90$

${ }^{2}$ The premium rebate varies between $5 \%$ and $20 \%$ depending on the insurer and the type of plan. In 2007, the average annual premium in Switzerland for the basic deductible was Sfr 3756.
} 
Figure 1: Number of insured per plan from 2003 to 2006

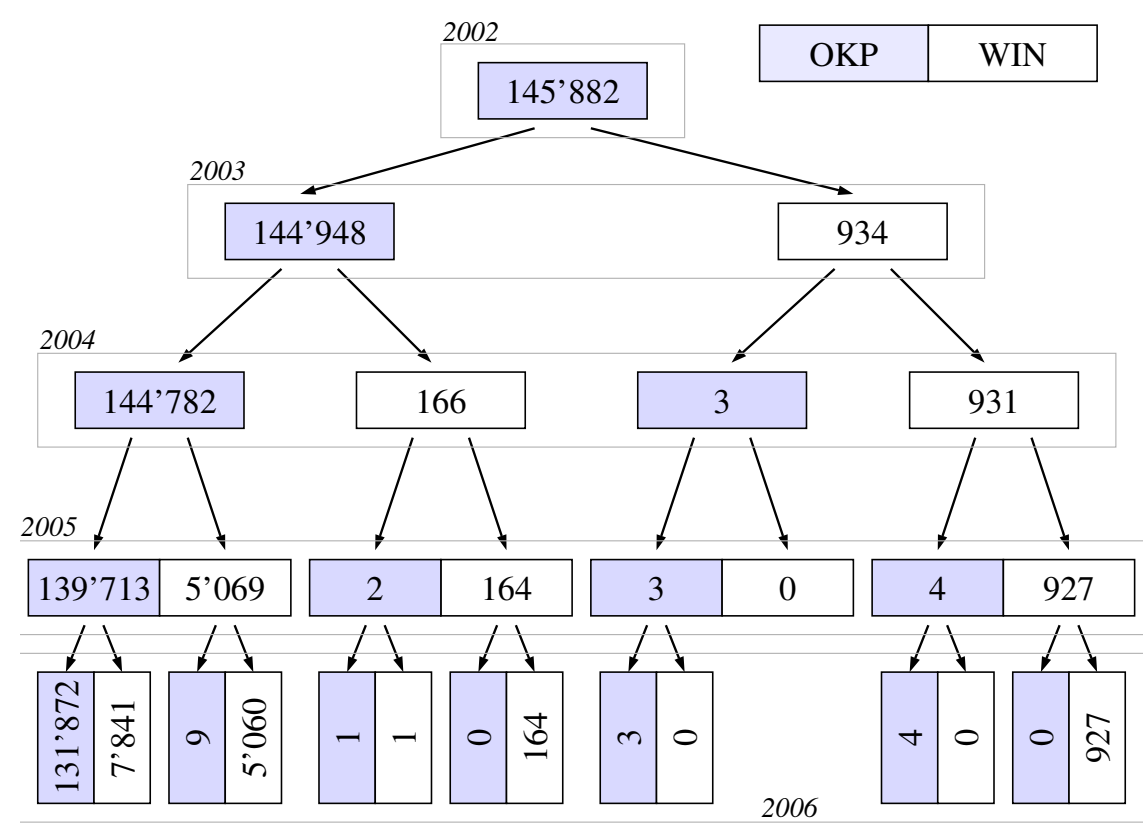

general practitioner); the latter was discontinued in 2003. Only a small share of the total insured chose the Winwin plan when it was launched $(4.2 \%$ in 2003). However, it should be noted that this share has increased over time (13\% in 2006). Figure 1 shows the movement across plans offered by KPT between 2003 and 2006 (for insured in the OKP plan in 2001 and 2002 only). It is clear from the figure that very few went back to the OKP plan after enrolling in the Winwin plan.

For each individual we observe the amount of yearly health care expenditure for the 2001-2006 period as known by KPT. We retain only those individuals who stayed with KPT during the entire observation period and continued to reside in the same canton. The data set contains information on 161462 insured adults, and covers a period of six years (2001 to 2006), i.e. a total of 968772 observations. We also examined information on 37782 children (0 to 18 years old), or 226692 observations for the same six-year period. It is reasonable to assume that this administrative data set is highly reliable since most of the health care invoices are sent to the insurer; inpatient and medication invoices are directly sent and paid by the insurer, while 
the insured must first settle any outpatient bills before forwarding them to the insurer for reimbursement. As usual, no "pure" health status variables are available, with the exception of observed spending.

Specifically, we observe the following variables:

- year of birth

- gender (1 represents men)

- insurance choice: insurance plan and deductible

- annual health care expenditures: outpatient, inpatient and medication separately

- type of expenditures: sickness, accident or maternity

- canton of residence

- subsidised premium (yes/no)

Since the use of telemedical services is assumed to have little impact on accidents and maternity care, we limited our examination to sickness-related data. Individuals who had selected the GP (general practitioner) managed care plan may have a different background and will be estimated separately. Similarly, given that the level of health expenditures, the deductible and the age effect on spending vary considerably between children and adults, we shall estimate a separate model for children.

Table 1: Health expenditures per year and per plan (Sfr)

\begin{tabular}{|c|r|r|r|r|r|r|r|}
\hline \multicolumn{2}{|c|}{ Total expenditures } & 2001 & 2002 & 2003 & 2004 & 2005 & 2006 \\
\hline \multirow{3}{*}{ Plan } & OKP & 2102 & 2302 & 2486 & 2983 & 3163 & 3430 \\
& Winwin & - & - & 1289 & 1654 & 1539 & 1648 \\
\cline { 2 - 8 } & All & 2102 & 2302 & 2435 & 2925 & 3037 & 3198 \\
\hline \hline \multicolumn{2}{|c|}{ Expenditures $>0$} & 2001 & 2002 & 2003 & 2004 & 2005 & 2006 \\
\hline \multirow{3}{*}{ Plan } & OKP & $79.85 \%$ & $80.65 \%$ & $80.71 \%$ & $80.51 \%$ & $81.72 \%$ & $81.84 \%$ \\
& Winwin & - & - & $68.68 \%$ & $69.97 \%$ & $67.79 \%$ & $70.11 \%$ \\
\cline { 2 - 8 } & All & $79.85 \%$ & $80.65 \%$ & $80.20 \%$ & $81.01 \%$ & $80.64 \%$ & $80.31 \%$ \\
\hline
\end{tabular}

Table 1 summarises the differences in average spending and the share of positive costs in each plan. This table shows that on average an individual 
in the Winwin plan has about half of the mean expenditure compared to an OKP plan enrolee. The proportion of positive expenditures is also lower in the Winwin plan.

\section{Empirical problematic}

This substantial difference in spending may be explained by three effects:

Selection effect Individuals in good health see the premium rebate as a gift, and therefore are more likely to select the Winwin plan, thus leading to lower average health expenditures compared to the OKP plan. This effect is due to self-selection rather than risk selection, as the insurer does not undertake any selection

Incentive effect There is no direct incentive effect since the coverage is exactly the same. However, as we shall see, the self-selected deductibles are higher for those who joined the Winwin plan, changing the average coverage in terms of co-payment. This leads to differences in the incentive effects which can go some way to explaining the varying health expenditure levels between the two plans

Efficiency effect Given that the telemedicine service provides medical advice, it may therefore prevent a futile physician visit or provide better guidance and timing in relation to health care use.

As we shall show, there is strong evidence of both selection and incentive effects in our data. To be able to evaluate the efficiency effect correctly, we need to control for the other two effects. Incentive effects are due to differences in the distribution of deductibles, and may easily be taken care of, since deductibles are observed variables. Other observed variables such as age and gender and deductibles may be used as proxies for the selection effect, but they proved to be bad proxies. Consequently, we constructed a model to control for unobserved selection effects.

\subsection{Strong evidence of selection effects}

Selection effects and selection bias are a frequent focus in the literature. Some authors found evidence of selection effects (Cutler and Zeckhauser (2000), Culter and Reber (1998), Cameron et al. (1988)), while others found none, e.g. Jones et al. (2002), Cardon and Hendel (2001) or Downd et al. (1991). However, research using Swiss data typically found evidence 
of selection effects (Gardiol et al. (2005b), Lehmann and Zweifel (2005), Werblow and Felder (2003), Schellhorn (2001)).

As already mentioned, we suspect that self-selection effects are at play here. In fact, the evidence is quite clear. Table 2 shows that younger individuals and relatively more men chose the Winwin plan compared to the OKP plan.

Table 2: Age and gender $(1=$ men $)$ per year and per plan

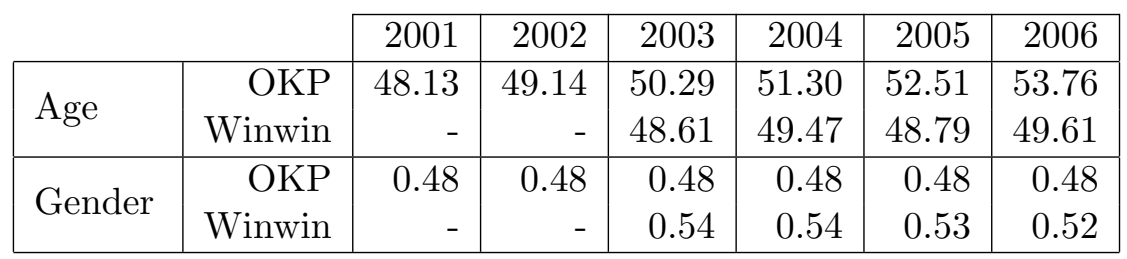

Moreover, if we compute the mean expenditures in 2002, depending on the future choice of plan in 2003, we obtain the results shown in table 3 (similar results are obtained for 2004 to 2006):

Table 3: Average health expenditure in 2002 according to choice of health insurance plan for 2003 (Sfr)

\begin{tabular}{|c|c|c|c|c|c|}
\hline & \multicolumn{4}{|c|}{ Average health expenditure in 2002} \\
\hline \multicolumn{2}{|c|}{ Deductible in 2002} & 230 & 600 & 1200 & 1500 \\
\hline Future plan & OKP & 2703 & 1634 & 892 & 766 \\
\hline in 2003 & Winwin & $1452 \quad 1173$ & 611 & 477 & 392 \\
\hline
\end{tabular}

People who will self-select the Winwin plan in the future already spend approximately half of what individuals who remain with the OKP plan, even after controlling for deductible differences. This may not be explained by efficiency and therefore provides clear evidence of a strong selection effect linked to health status or at least to health consumption behaviour.

\subsection{Evidence of incentive effects}

Table 4 presents the mean deductible per year and per plan. The deductible is a discrete variable since only six different levels are set by law. An average 
deductible does not represent the real value of a deductible but rather a fictional number which provides information on the average coverage chosen by the insured. As we already know, self-selection does occur: the healthier opt for the Winwin plan and the insured in general choose their deductible level based on their health status (see Gardiol and al. (2005a)). Therefore, we were not surprised to observe a higher average deductible in the Winwin plan compared to the OKP plan.

Table 4: Average deductible chosen by the insured by year and by plan (Sfr)

\begin{tabular}{|l|r|rrrr|}
\cline { 3 - 6 } \multicolumn{2}{l|}{} & 2003 & 2004 & 2005 & 2006 \\
\hline Average & OKP & 468 & 528 & 593 & 605 \\
deductible & Winwin & 748 & 829 & 1134 & 1179 \\
\hline
\end{tabular}

Since the distribution of deductibles is different for the Winwin and the OKP plan, regardless of the year of observation, Winwin plan enrolees face stronger monetary incentives than those in the traditional plan. Although merely an indirect effect of this plan, it still means that Winwin enrolees spend less on health care (Newhouse (1996), Gardiol et al (2005b), Cardon and Hendel (2001)). Both this and the selection effect must be controlled for.

\section{Estimation of the efficiency effect}

\section{$5.1 \quad$ Model}

We estimate a two-step model for all the years of observations. The first step involves a logistic model for health care use, while the second is concerned with a linear regression for positive spending. The expected efficiency gains are additive by nature, which means that they mainly reflect saved physicians visits but are not a percentage of spending. We therefore chose to estimate a linear over the usual log-linear model to obtain the additive rather than the multiplicative efficiency effect. We control for all other sources of explanation of the correlation between health expenditures and the choice of the insurance plan, age, gender, time inflation, deductibles, subsidised premiums and the cantonal dummies to control for the regional effects (differences in tariffs, behaviours, ...). Time variables are introduced in the model as time dummies, with 2006 as the reference period. Since the level 
of deductibles was changed by law twice during the period concerned ${ }^{3}$, we decided to classify them into four groups in order to avoid some collinearity between the time and deductible dummies:

- reference group: basic levels of deductibles (Sfr 230, 300)

- ded_low: low level of deductibles (Sfr 400, 500, 600)

- ded_mid: middle level of deductibles (Sfr 1 000, 1 200)

- ded_high: high level of deductibles (Sfr 1 500, 2 500)

The selection effect is not well explained by any of the available variables. However, we were fortunate to observe at least two years of spending behaviour prior to selection. During this first period, the difference in expenditures (corrected for the deductible levels) merely reflects the selection effect. After self-selection, the difference in expenditures (corrected for the deductible levels) reflects the sum of the selection and efficiency effects. The discrepancy between the differences in spending behaviour during the two periods is therefore the efficiency effect.

The dummy variable "select" takes the value 0 for an individual who never chose the Winwin plan and the value 1 for an individual who chose to enrol with the Winwin plan for at least one year.

The dummy variable "win" takes the value of 0 if the individual is not in the Winwin plan during the year of observation, and the value of 1 if the individual is in the Winwin plan ${ }^{4}$.

To illustrate the construction of these two variables, let us consider three examples:

1. Ms Poorly is 65-years' old and frequently visits her physician. She did not enrol with the Winwin plan as she preferred to remain with the traditional OKP plan.

2. Ms Happy is 40-years' old and she immediately chose the Winwin plan in 2003 to benefit from a premium rebate. Since she was happy with

\footnotetext{
${ }^{3}$ The basic deductible changed from SFr 230 to 300 on 1st January 2004. In addition all deductible levels changed from SFr 300, 400, 600, 1200 and 1500 to SFr 300, 500, $1000,1500,2500$ on 1st January 2005.

${ }^{4}$ Note that there is no punishment for non-compliance in the Winwin plan. In this study, individuals who went to a physician without calling the telemedicine centre first are nevertheless kept in the Winwin sub-sample although they do not benefit from the telemedicine service.
} 
this model, she stayed in the Winwin plan for the entire observation period.

3. Mr Stressed is 30-years' old and very busy. He missed the opportunity to choose the Winwin plan in 2003 but chose it in 2004. Since he always forgot to call the telemedicine centre before visiting a physician, he returned to the OKP plan in 2005.

According to these three examples, we obtain the dummy variables for "select" and "win" presented in table 5.

Table 5: Examples of constructed variables select and win

\begin{tabular}{|c|cc|cc|cc|}
\cline { 2 - 7 } \multicolumn{1}{c|}{} & \multicolumn{2}{c|}{ Ms Poorly } & \multicolumn{2}{c|}{ Ms Happy } & \multicolumn{2}{c|}{ Mr Stressed } \\
\hline Year & select & win & select & win & select & win \\
\hline 2001 & 0 & 0 & 1 & 0 & 1 & 0 \\
2002 & 0 & 0 & 1 & 0 & 1 & 0 \\
2003 & 0 & 0 & 1 & 1 & 1 & 0 \\
2004 & 0 & 0 & 1 & 1 & 1 & 1 \\
2005 & 0 & 0 & 1 & 1 & 1 & 0 \\
2006 & 0 & 0 & 1 & 1 & 1 & 0 \\
\hline
\end{tabular}

These variables split the observations into three different groups:

Select $=\mathbf{0}, \mathbf{W i n}=\mathbf{0}$ People who stayed in the OKP plan for the entire period

Select $=\mathbf{1}, \mathbf{W i n}=\mathbf{0}$ People who opt for the Winwin plan for at least one year but who are not in the Winwin plan that year

Select $=1$, Win=1 People choosing at least one year the Winwin plan and who are in the Winwin plan that year

The selection effect can be identified by comparing the health expenditures of the first two groups (in particular prior to selecting the Winwin plan), while the efficiency effect can be identified by comparing the health expenditures of the last two groups (mainly after selecting the Winwin plan). 


\subsection{Results}

We shall present only the results of the main estimation, i.e. the twostep model for adults who chose the OKP plan in 2001 and 2002. The estimations for those already in the GP plan and for children are presented in the Appendix. Table 6 presents the results of the two-step estimation. The first step is a logistic estimation and the table 6 presents the results as odds ratios ${ }^{5}$, while the second step is a linear estimation.

Table 6: Two-step estimation of health expenditure

\begin{tabular}{|c|c|c|c|c|}
\hline & \multicolumn{2}{|c|}{ Logistic $(\mathrm{N}=875292)$} & \multicolumn{2}{|c|}{ OLS $(\mathrm{N}=706245)$} \\
\hline & Odds Ratio & $\mathrm{Z}$ & Coefficient & $\mathrm{t}$ \\
\hline win & 1.0292 & 1.49 & -234.49 & -3.72 \\
\hline select & 0.8963 & -10.50 & -702.60 & -21.65 \\
\hline age & 1.0315 & 152.84 & 79.01 & 161.60 \\
\hline gender & 0.4017 & -152.46 & -86.99 & 5.56 \\
\hline subvention & 1.0178 & 2.05 & 767.05 & 32.89 \\
\hline ded_low & 0.6709 & -52.56 & -719.42 & -35.62 \\
\hline ded_mid & 0.3054 & -73.41 & -1512.14 & -25.24 \\
\hline ded_high & 0.2663 & -170.38 & -1724.94 & -62.49 \\
\hline D2001 & 0.9023 & -9.84 & -1121.29 & -40.67 \\
\hline D2002 & 0.9538 & -4.51 & -968.15 & -35.29 \\
\hline D2003 & 0.9779 & -2.14 & -766.05 & -28.06 \\
\hline D2004 & 1.0318 & 2.99 & -270.56 & -9.96 \\
\hline D2005 & 1.0275 & 2.63 & -163.64 & -6.08 \\
\hline constant & & & 44.19 & 1.16 \\
\hline \multicolumn{5}{|c|}{... and dummies for canton } \\
\hline
\end{tabular}

In both steps the "select" variable has a negative effect on health expenditure, meaning that even when controlling for age, gender and deductible, the remaining selection effects continue to be highly significant. The results show that an [Select=1, Win=0] individual has an $11 \%$ lower chance of having a positive expenditure and spends about Sfr 700 less on health care compared to an $[$ Select $=0$, Win $=0]$ individual with the same age/gender/deductible.

\footnotetext{
${ }^{5}$ We present the odds ratios instead of the coefficients of the associated logit model in order to facilitate the interpretation of the results. We therefore expect the odds ratios to be lower than one for negative logit coefficients and higher than one for positive logit coefficients. The difference with respect to one can be directly interpreted as a \% change of the variable
} 
This selection effect reflects differences in health status across both plans.

The coefficient of the variable "win" can be interpreted as the efficiency effect of the Winwin plan. The estimation shows that the probability of having positive expenditures is not lowered by the Winwin plan. However, the average amount spent by an individual with a positive expenditure is reduced by more than Sfr 200 in the Winwin plan. Taking the two steps together, we find that the Winwin plan has an average efficiency effect of Sfr 153 per individual per year. In Switzerland, this amount corresponds to approximately two visits to a general practitioner or one visit to a specialist.

As expected, age has a positive effect on health expenditures and is highly significant in both steps of the estimation. Men have a lower probability of having positive health expenditures. Even when this is the case, they spend less than women. The subsidy variable is negatively related to income and shows that individuals in receipt of a subsidy (low-income bracket) spend more than individuals whose insurance premiums are not subsidised. The deductible groups present the usual decreasing pattern with respect to the deductible level. This, however, merges the three effects. The selfselection of the deductible reflecting good health, the incentive effect due to the higher co-payment rate, and part of the selection effect of the Winwin plan, since the deductible reflects health status and selection of this plan also depends on this factor. The exact amounts of these three effects cannot be estimated, but the main purpose of these variables is to control for the difference in incentives, which is exactly what we did. Finally, the time dummies show a significant rise in the amount of care delivered over time. The coefficients of the cantonal variables are presented in the Appendix.

The efficiency of the plan is estimated at SFr 153. Information on the cost of the telemedicine service is confidential. However, the public price of the telemedicine service for a whole family is valued at SFr 150 per year, which is more than what is charged at the KPT, and logically is more than the costs of the service. The inclusion of the telemedicine service has reduced health spending costs and is cost-effective, in other words the health cost reduction is greater than the costs of the service.

\subsection{Who wins?}

The overall efficiency gain is estimated at Sfr 153. But who is actually saving this money? If the gain is realized under the deductible level, the whole amount will be saved by the insured. If this gain is realized above the cap, only the insurer benefits. If the gain is realized between the deductible level and the cap, $90 \%$ goes to the insurer and $10 \%$ to the insured (corresponding 
to the $10 \%$ co-payment after the deductible level is reached). We forecasted the spending and the OoP (Out of Pocket payment) with the true data for Winwin enrolees. We also forecasted the amount of spending and OoP they would have had according to the model if they had stayed in the OKP plan. Table 7 presents the distribution of the efficiency gain between insured and insurer.

Table 7: Distribution of the efficiency gain between insured and insurer

\begin{tabular}{r|rr|r|} 
& Insurer & Insured & Total \\
\hline Predicted gain & 90 & 63 & 153 \\
Percentage & $59 \%$ & $41 \%$ & $100 \%$ \\
\hline
\end{tabular}

The amount saved by the insurer is still higher than the costs, which means that the insurer has a net gain generated by the introduction of a telemedicine service.

Without the telemedicine service there would have been a certain number of physician visits $(\mathrm{N})$, but since it is easier to phone the call centre than to meet the physician face-to-face, the number of calls will be higher than the number of medical visits $(\mathrm{N}+\mathrm{p})$. Furthermore, the calls may result in a reduction in medical visits $(\mathrm{N}+\mathrm{p}-\mathrm{r})$. Overall, the model shows a decrease in medical visits, so that $(r>p)$. The plan therefore saves futile physician visits being made.

\section{Conclusion}

We have seen that the average health expenditures of the Winwin plan is about Sfr 1500 and represents half of the average health expenditures of the OKP plan. $90 \%$ of this Sfr 1500 difference can be attributed to selfselection and incentive effects, while $10 \%$ can be explained by efficiency (that is approx. Sfr 150 of efficiency gain per year). Moreover, the self-selection effect is considerable, at least three times higher than the efficiency effect, if we take only the "pure" select effect. Given that this managed care plan attracts many healthy individuals, a certain degree of risk selection does occur through self-selection.

The introduction of a mandatory telemedicine service to a fee-for-service plan reduces health costs and is cost-effective. The efficiency effect is small in comparison to the increase in costs through time. Consequently, this 
innovation may curb but certainly does not stop the increase of health expenditures. However, according to our research which focused solely on monetary gain, both the insured and the insurer benefit.

This plan also offers non-monetary gains. Firstly, the insured receive better information since they make greater use of the telemedical service than they would a physician and, secondly, they save on actual consultations. With each saved physician visit, the patient also saves on travel costs and waiting times, not to mention lower anxiety levels due to the advice dispensed by the health professionals at the telemedicine call centre. This only benefits the insured. The non-monetary cost of the plan is the time of a phone call, and constitutes a pure loss if it is followed by a visit to a physician. Good triage and time management may prevent or reduce some inpatient stays in the long run, so much so that the state may also save on public hospital subsidies (presently the state covers $50 \%$ of inpatient bills). There is no clear evidence of such an effect in the data set, but we are certainly not in the long run yet. The insurer is finally not the ultimate winner, even when its costs are covered. In fact, the insured benefit from better information, save non-monetary and monetary costs, as well as enjoy lower premiums.

Finally, the method proposed in this paper distinguishes between selectionincentive and efficiency effects and may be used to compare any managed care plan. 


\section{References}

[1] J. Buchanan, A. Leibowitz, and J. Keesey. Medicaid health maintenance organizations: can they reduce program spending? Medical Care, 34(3):249-263, 1996.

[2] A. Cameron, P. Trivedi, F. Milne, and J. Piggott. A microeconometric model of the demand for health care and health insurance in australia. Review of Economic Studies, 55:85-106, 1988.

[3] J.H. Cardon and I. Hendel. Asymmetric information in health insurance: evidence from the national medical expenditure survey. $R A N D$ Journal of Economics, 32(3):408-427, 2001.

[4] D. Culter and R. Zeckhauser. The anatomy of health insurance. In A. Culyer and J. Newhouse, editors, Handbook of Health Economics, volume 1A. North Holland, 2000.

[5] D. Cutler and S.J. Reber. Paying for health insurance: The trade-off between competition and adverse selection. The Quarterly Journal of Economics, 113(2):433-466, 1998.

[6] P. Deb, C. Li, P. Trivedi, and D. Zimmer. The effect of managed care on use of health care services: Results from two contemporaneous household surveys. Health Economics, 15:743-760, 2006.

[7] L. Gardiol, P.-Y. Geoffard, and C. Grandchamp. Insurance: Theoretical Analysis and Policy Implications, chapter Selection and incentive effects: an econometric study of Swiss health insurance claims data. MIT Press, 2005a.

[8] L. Gardiol, P.-Y. Geoffard, and C. Grandchamp. Separating selection and incentive effects in health insurance. CEPR - Discussion paper, 5380, 2005b.

[9] A.M. Jones, X. Koolman, and E. Van Doorslaer. The impact of private health insurance on specialist visits: analysis of the european community household panel (echp). Working Paper 9, ECuity II Project, 2002.

[10] H. Lehmann and P. Zweifel. Insurance: Theoretical Analysis and Policy Implications, chapter Choice of managed care and cost savings: The role of latent health status. MIT Press, 2005. 
[11] W. Manning, J. Newhouse, N. Duan, E. Keeler, A. Leibowitz, and S. Marquis. Health insurance and the demand for medical care: Evidence from a randomized experiment. AER, 77:251-277, 1987.

[12] J. Newhouse and The Insurance Experiment Group. Free for all? Lessons from the RAND Health Insurance Experiment. Harvard University Press, Cambridge, MA, 1996.

[13] M. Schellhorn. The effect of variable health insurance deductibles on the demand for physicians visits. Health Economics, 10:441-456, 2001.

[14] J. Shin and S. Moon. Do hmo plans reduce health care expenditure in the private sector? Economic Inquiry, 45(1):82-99, 2007.

[15] A. Werblow and S. Felder. Der einfluss von freiwilligen selbstbehalten in der gesetzlichen krankenversicherung: Edivenz aus der schweiz. Zeitschrift fur Wirstschafts und Sozialwissenschaften, 123(2):235-264, 2003. 


\section{Appendix}

\subsection{Results for the canton dummies - main estimation}

Table 8 presents the coefficients and t-test associated with the canton dummies introduced as explanatory variables in the main two-step regressions. The coefficients adequately represent the levels of spending in each canton directly linked to premium levels.

Table 8: Canton dummies for the main regression (reference: Bern)

\begin{tabular}{|c|c|c|c|c|c|c|}
\hline & \multicolumn{3}{|c|}{ Logistic estimation $\left(\mathrm{N}=875^{\prime} 292\right)$} & \multicolumn{3}{|c|}{ OLS estimation $\left(\mathrm{N}=706^{\prime} 245\right)$} \\
\hline & Odds Ratio & Std. Err. & $\mathrm{z}$ & Coefficient & Std. Err. & $\mathrm{t}$ \\
\hline $\mathrm{AG}$ & 1.0125 & 0.0194 & 0.65 & -150.41 & 54.42 & -2.76 \\
\hline AI & 0.6417 & 0.0672 & -4.24 & -1211.68 & 323.61 & -3.74 \\
\hline $\mathrm{AR}$ & 0.6584 & 0.0250 & -11.01 & -888.97 & 110.15 & -8.07 \\
\hline BL & 1.3940 & 0.0294 & 15.74 & 13.91 & 54.51 & 0.26 \\
\hline BS & 1.4207 & 0.0492 & 10.13 & 752.55 & 83.40 & 9.02 \\
\hline FR & 1.6099 & 0.0243 & 31.57 & -141.06 & 37.44 & -3.77 \\
\hline GE & 1.8368 & 0.0268 & 41.70 & 1098.50 & 33.81 & 32.49 \\
\hline GL & 0.9430 & 0.0594 & -0.93 & -959.98 & 171.99 & -5.58 \\
\hline GR & 1.3197 & 0.0214 & 17.13 & -454.42 & 39.88 & -11.40 \\
\hline $\mathrm{JU}$ & 1.3839 & 0.0623 & 7.22 & 446.58 & 107.67 & 4.15 \\
\hline LU & 0.8047 & 0.0134 & -13.01 & -530.90 & 50.04 & -10.61 \\
\hline $\mathrm{NE}$ & 1.3869 & 0.0629 & 7.21 & 881.19 & 91.26 & 9.66 \\
\hline NW & 0.7631 & 0.0264 & -7.83 & -702.89 & 105.15 & -6.68 \\
\hline OW & 0.8400 & 0.0555 & -2.64 & -534.52 & 206.32 & -2.59 \\
\hline SG & 1.2208 & 0.0208 & 11.71 & -616.92 & 45.43 & -13.58 \\
\hline $\mathrm{SH}$ & 1.0235 & 0.0500 & 0.48 & -163.70 & 131.99 & -1.24 \\
\hline $\mathrm{SO}$ & 1.0184 & 0.0171 & 1.09 & -361.93 & 48.30 & -7.49 \\
\hline $\mathrm{SZ}$ & 1.0620 & 0.0393 & 1.63 & -527.12 & 104.04 & -5.07 \\
\hline TG & 0.9479 & 0.0278 & -1.82 & 97.13 & 82.66 & 1.18 \\
\hline $\mathrm{TI}$ & 1.6963 & 0.0175 & 51.22 & 353.35 & 26.56 & 13.30 \\
\hline UR & 0.8337 & 0.0369 & -4.11 & -980.43 & 125.27 & -7.83 \\
\hline VD & 1.5873 & 0.0183 & 40.15 & 510.20 & 28.66 & 17.80 \\
\hline VS & 1.3208 & 0.0203 & 18.11 & -620.04 & 38.44 & -16.13 \\
\hline ZG & 0.8389 & 0.0286 & -5.16 & -325.97 & 105.38 & -3.09 \\
\hline $\mathrm{ZH}$ & 1.0570 & 0.0104 & 5.65 & -112.67 & 28.17 & -4.00 \\
\hline
\end{tabular}




\subsection{Results for adult individuals choosing the GP plan in 2001-2002}

The same model was estimated for adult individuals choosing the GP model in 2001 or/and in 2002. In 2003, the Winwin plan replaced the GP plan; some of the enrolees then chose the Winwin plan, while others preferred the OKP plan. Since they selected a managed care plan in 2001 or/and 2002, they already revealed some unobserved characteristics compared to those who chose the OKP plan in 2001 and 2002. We expect therefore another value for the coefficient of the variable "select" with regard to the reference estimation. Table 9 presents the results for the two variables of interest.

Table 9: Estimation for adults individuals in the GP plan in 2001/2002

\begin{tabular}{|r|r|r|r|}
\hline \multicolumn{4}{|c|}{ Logistic estimation (N=93 474) } \\
\hline Prob(Y $>0)$ & Odds Ratio & Std. Err. & $\mathrm{z}$ \\
\hline win & 0.9236 & 0.0280 & -2.63 \\
select & 0.7634 & 0.0187 & -11.00 \\
\hline \multicolumn{4}{|c|}{ OLS estimation (N=71 741) } \\
\hline Y $>0$ & Coefficient & Std. Err. & $\mathrm{t}$ \\
\hline win & -106.47 & 80.44 & -1.32 \\
select & -446.35 & 64.60 & -6.91 \\
\hline
\end{tabular}

If we regroup both steps of the estimation, we obtain an overall efficiency effect of Sfr 101 for the subpopulation who chose the GP plan in 2001 or/and 2002. This shows that those participating in the GP plan in the past already had "better" health service consumption behaviour, so there was less to be saved. Again one can distribute this efficiency gain between the insured and the insurer. Using the predicted costs, we obtain a Sfr 68 (67\%) gain for the insurer and the remaining Sfr 33 (33\%) gain for the insured.

\subsection{Results for children}

We now regress on the children sub-sample (for those who chose the OKP plan in 2001 and 2002). We suspect that the selection effect is smaller than for adults, since generally the whole family selects the Winwin plan, and greater weight is probably given to the health status of the parents when deciding to opt for the Winwin plan or not. Table 10 presents the results for the two main variables for the children estimation. 
Table 10: Estimation of the two-step model for children

\begin{tabular}{|r|r|r|r|}
\hline \multicolumn{4}{|c|}{ Logistic estimation (N=207 420) } \\
\hline Prob(Y $>0$ ) & Odds Ratio & Std. Err. & $\mathrm{z}$ \\
\hline win & 0.8989 & 0.0293 & -3.27 \\
select & 0.9230 & 0.0183 & -4.04 \\
\hline \multicolumn{4}{|c|}{ OLS estimation (N=167 789) } \\
\hline Y $>0$ & Coefficient & Std. Err. & t \\
\hline win & -73.60 & 40.60 & -1.81 \\
select & -176.24 & 22.58 & -7.81 \\
\hline
\end{tabular}

Average expenditure levels are much lower for children than for adults. Furthermore, since the age and gender effect are also different, their exclusion from the "general" sample was justified. We obtain an overall significant efficiency effect of Sfr 68 , which corresponds to about $12 \%$ of average expenditure in the Winwin plan. However, since most of the children had no deductible at all (the basic deductible level for children is zero), the insurer benefited much more from the gain $(82 \%)$ than the insured $(18 \%)$. The selection effect is indeed lower, about 2.3 times the efficiency effect (but three times for adult individuals). 


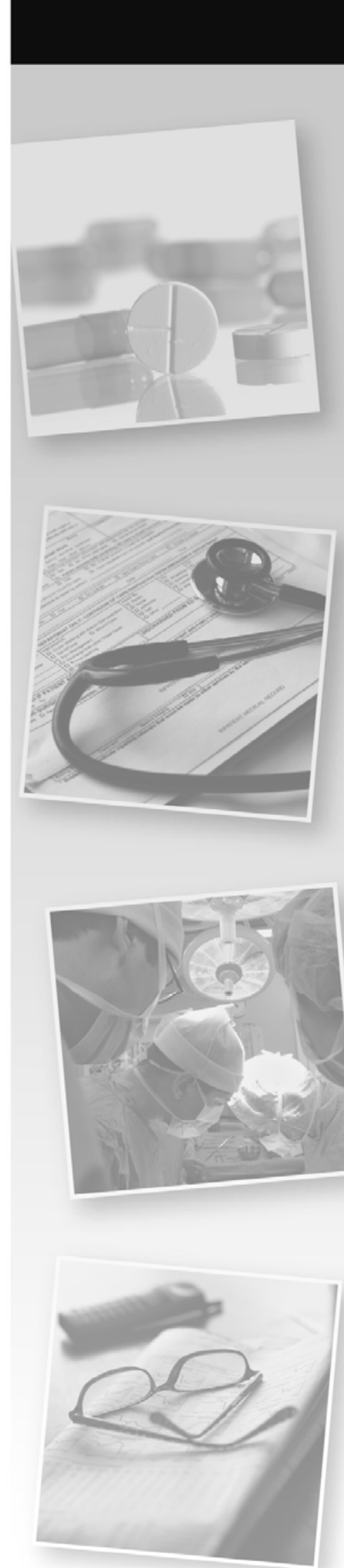

Institute of Health Economics and Management (IEMS)

UNIL Dorigny

Extranef

1015 Lausanne

Switzerland

Phone +41 (0)21 6923320

Fax +41 (0)21 6923655

www.hec.unil.ch/iems 